\title{
Effect of UV-Irradiation on Fluorescence of Poly (Para-Ethoxystyrene) Films with Phthalate and Terephthalate Plasticizers
}

\author{
Khalid E. Al Ani ${ }^{1}$, Wadhah N. Al Sieadi ${ }^{2}$, Thanaa M. Al Mouamin ${ }^{2}$ and Afrah Essa Ramadhan ${ }^{3}$ \\ 1. Department of Pharmaceutical Chemistry, Faculty of Pharmacy, Jadara University, Irbid 21110, Jordan \\ 2. Department of Chemistry, Faculty of Science, Baghdad University, Baghdad 10071, Iraq \\ 3. Department of Industrial Chemistry, Institute of Technology, Baghdad 10071, Iraq
}

\begin{abstract}
The photodegradation of irradiated thin films of poly (para-ethoxystyrene) with $265 \mathrm{~nm}$ radiations in the presence of air and as a function of irradiation time has been studied using UV-VIS, fluorescence and FT-IR spectroscopic techniques. The increase in irradiation time caused an increase in the intensity of the absorption band of the polymer, thus indicating a possibility of photodegradation of polymeric chains. The influence of increase in irradiation times on pure poly (ethoxystyrene) films caused a decrease in the intensity of the fluorescence band and the appearance of new broad band at longer wavelength and to decrease with increase in irradiation time. The influence of added phthalate and terephthalate plasticizers on photo-oxidative degradation was also investigated, and found to increase the photodegradation processes in polymeric chains. The photo-quenching rate constant was found to increase with the increase of the molar mass and bulkiness of the used plasticizers and to increase with the increase in irradiation time. The rate constant of the photo quenching process was found to decrease with the increase in the amount of added plasticizers, indicating that the added plasticizers may act as UV-absorbers which inhibit the photodegradation process. The analysis of the FT-IR spectra of the irradiated and non-irradiated samples, showed a noticeable formation of new bands, and their intensity was found to increase with the increase in irradiation time and also with the increase in the amount of added plasticizer. In addition, the observed increase in the intensities of the carbonyl and hydroxyl absorption regions of the FT-IR spectra, provide evidence for the photodegradation as well as photo-oxidation of polymeric chains.
\end{abstract}

Key words: Excimer fluorescence, FT-IR spectroscopy, photodegradation kinetics, phthalate plasticizers, poly (4-ethoxystyrene).

\section{Introduction}

The investigation of photodegradation of polystyrene and substituted polystyrene in solid films and in presence of air have been studied in details by many researchers [1-5]. Substituted polystyrene is widely used for the preparation of polymeric reagents, plastic recycling and industrial uses. Several studies have been conducted on the photodegradation of substituted polystyrene and are of interest for the photo stability of these polymers and for the preparation of new polymers which may be relevant to industrial applications [6-10]. It was reported that the

Corresponding author: Khalid E. Al Ani, Ph. D., professor, research fields: physical pharmacy, stability of martial science. photodegradation of substituted polystyrene was similar to that of polystyrene, and occurs as a result of the formation of excited chromophores followed by other processes such as photo-oxidation, chain scission and cross linking [11-15].

Irradiated polymeric chromophores by UV-light energy can initiate the formation of excited chromophores which can produce free radicals in the polymer backbone. The quantum energies associated with light in the UV region are sufficient to break many of the chemical bonds present in polymer chromophores. The formed free radicals can react with atmospheric oxygen to produce serried reactions that lead to distraction of polymeric chains $[13,16]$. Oxidative degradation of chains can lead to the 
formation of various oxygen-containing functional groups, such as peroxides and carbonyls [17-20].

It is well known that blending of substituted polystyrene (SPS), and polystyrene with phthalate and terephthalate plasticizers accelerates the photogegradation of irradiated polymeric chromophores in solid films [21-24]. It was also found that the photo-stability of polystyrene was reduced by the addition by bromine-containing flame retardant, and appeared to depend on the chemical structure of the additive [22]. For the photodegradation of polystyrene containing carbonyl group, it was found that the efficiency of degradation of polymeric chromophores increased with the increase in the exposure time, and showed a change in the average molecular weight as a consequence of chain dissociation. The photodegradation of halogen substituted styrene in solid films showed a degradation of polymeric chromophores and is enhanced by plasticization with phthalate and terephthalate plasticizers $[25,26]$. The irradiated polymers showed a yellowish discoloration caused by irradiation; this was related to the formation of chain double bonds as a result of hydrogen atom abstraction from the $\mathrm{C}$-atom in $\gamma$ position of the phenyl group. It was also observed that the photodegradation of poly (p-tert-butylstyrene) solid films with $254 \mathrm{~nm}$ radiation, under high vacuum had been studied. The main evolve gas is hydrogen, little amount of methane, ethane, and isobutene are also formed, indicating that fission of bonds in the tert-butyl group has occurred [23].

In this study, we are interested in studying the various aspects of photodegradation of pure poly (para-ethoxystyrene) and blended polymer with phthalate and terephthalate plasticizers in solid films, and have advanced our studies as described in this article. The stability of blended polymeric films with phthalates and terephthalate plasticizers were also investigated with the following aims:

(1) To investigate the effect of ring substitution on the photostability of irradiated pure and blended poly (para-ethoxystyrene) with UV light energy in presence of air.

(2) To select the best polymeric additive from phthalate and terephthalate plasticizers that can cause less photodegradation effect on the irradiated polymeric solutions.

(3) To compare the photostability of poly (para-ethoxystyrene) (PEOXS) with that of other substituted polystyrene.

(4) To apply Al Ani-Hawi relation [8], in order to evaluate some kinetic parameters such as photo quenching rate constant, and quenching efficiencies of irradiated pure and blended polymer solution.

\section{Experimental}

\subsection{Materials}

The sample of para-ethoxystyrene monomer has been purchased from Across-Organics with high purity. Before polymerization, the sample was distilled under reduced pressure in the presence of pure nitrogen and stored in the dark at $0.0{ }^{\circ} \mathrm{C}$. The poly (4-ethoxystyrene) (PETOS) was synthesized by bulk polymerization using $1.0 \%$ Azobisisobutyronitrile (AIBN) as indicator at $50{ }^{\circ} \mathrm{C}$. The average molar mass of the obtained polymer was $\left(\mathrm{Mn}=3.36 \times 10^{4} \mathrm{~g} /\right.$ mole, and $\mathrm{Mw}=5.16 \times 10^{4}$ $\mathrm{g} / \mathrm{mole})$. Only spectroscopic grade dichloroethane (DCE) was used in casting the solid films. It was found to give no detectable absorption in range (250-400 nm). It was purchased from Fluka GMBH and was used as received. The used plasticizers are dimethyl terephthalate (DMT), diethyl terephthalate (DET), dioctyl terephthalate (DOT), dibutyl phthalate (DBP) and dioctyl phthalate (DOP). These were of high purity of about $(99.8 \%)$, and were purchased from Across-Organics and found to give no detectable absorption in rang 260-400 $\mathrm{nm}$.

\subsection{Preparation of Plasticized Polymeric Solid Films}

Poly (para-ethoxystyrene) thin films with thickness of approximately $0.02 \mathrm{~mm}$ were prepared by solution 
casting of $20 \mathrm{wt} \%$ polymer in DCE on a spectroscopic window (quartz plate of $1.0 \mathrm{~mm} \times 20 \mathrm{~mm}$ diameter). Moreover, about $0.02 \mathrm{~mm}$ thick PETOS-plasticizer films, containing different $\mathrm{wt} \%$ plasticizers were prepared by solution casting of \{polymer + (1.0-5.0 $w t \%)$ of added plasticizer $\}$ in DCE solvent. These films were used as to gain better insight into the possibility of photodegradation of the polymer during irradiation. The films were dried in a vacuum oven at $293 \mathrm{~K}$ for 24 hours, as to ensure the complete removal of solvent traces [9].

\subsection{Absorption and Fluorescence Spectra Measurements}

Absorption spectra in the UV-range have been recorded for PETOS solid films before and immediately after UV irradiation with a Cary 100 Bio UV-visible Spectrophotometer at $298 \mathrm{~K}$.

Emission spectra of UV-irradiation were preformed on a JASCO-FP $6500 \quad$ Fluorescence Spectrofluorometer at room temperature. The parameters were constant for all measurements, and the excitation wavelength was $265 \mathrm{~nm}$. The emission wavelength range was 270-400 $\mathrm{nm}$, and all fluorescence spectra for the solid films were obtained using a thermostated solid sample holder.

\subsection{UV-Vis Spectroscopy}

Absorption spectra in the UV-visible range have been recorded using a JASCO-Spectrofluorometer with a built in Hydrogen-Xenon lamp (6808-J007A model number ESC-333), and supported with monochromator of holographic grating with 1,800 groves $/ \mathrm{mm}$. The measurements of pure polymer and that for used plasticizers were preformed in dichloroethane solution. Polymeric films were UV-irradiated for different intervals of time, from (0.0-3.0 hours), and supported with monochromator of holographic grating with 1,800 groves $/ \mathrm{mm}$. The intensity of the incident light, measured by HD 9021 radiometer was $1.55 \mathrm{~mW} / \mathrm{cm}^{2}$. The irradiation was carried out at $298 \mathrm{~K}$ and at ambient atmosphere.

\subsection{Measurements of FT-IR-Spectra}

The Fourier transform infrared spectroscopy system that was employed in this work was NICOLET-MAGNA-IR-560 spectrometer, while the transmission mode was employed in these measurements. The working wavenumber range of the spectrometer was from 4,000 to $500 \mathrm{~cm}^{-1}$, with a resolution of $2 \mathrm{~cm}^{-1}$. The FT-IR spectra were recorded for the irradiated and the non-irradiated films, whereas the transmittance was plotted as function of the wavenumber.

\section{Results and Discussion}

\subsection{UV-Absorption Spectra of Pure Poly (4-Ethoxystyrene), Phthalate and Terephthalate} Plasticizers in DCE Solution

The UV-Absorption spectra of the used phthalate and terephthalate plasticizers in dichloroethane solutions containing $10 \% \mathrm{w} / \mathrm{w}$ at room temperature are shown in Fig. 1.

In order to evaluate the optical properties of PETOS, absorption spectra of pure and plasticized polymer have been collected in the range of $(260-450 \mathrm{~nm})$. The spectra provide information about absorption of chromophoric groups present in the structure of photoinitiators and possibility of their excitation upon UV. It is necessary for occurrence of the fluorescence in these compounds. The shape of the absorption spectrum is similar to that of polystyrene, with small changes in the maxima of the absorption spectrum. This may be due to the chemical structure of the substituted group in phenyl ring. The region of absorption of the used phthalate and terephthalate was found in the region of (220-260 nm) as shown in Fig. 1. All the used plasticizers absorb radiation below $260 \mathrm{~nm}$. According to this, the selected excitation wavelength for PETOS was $265 \mathrm{~nm}$, in order to avoid the absorption of the used plasticizers. 


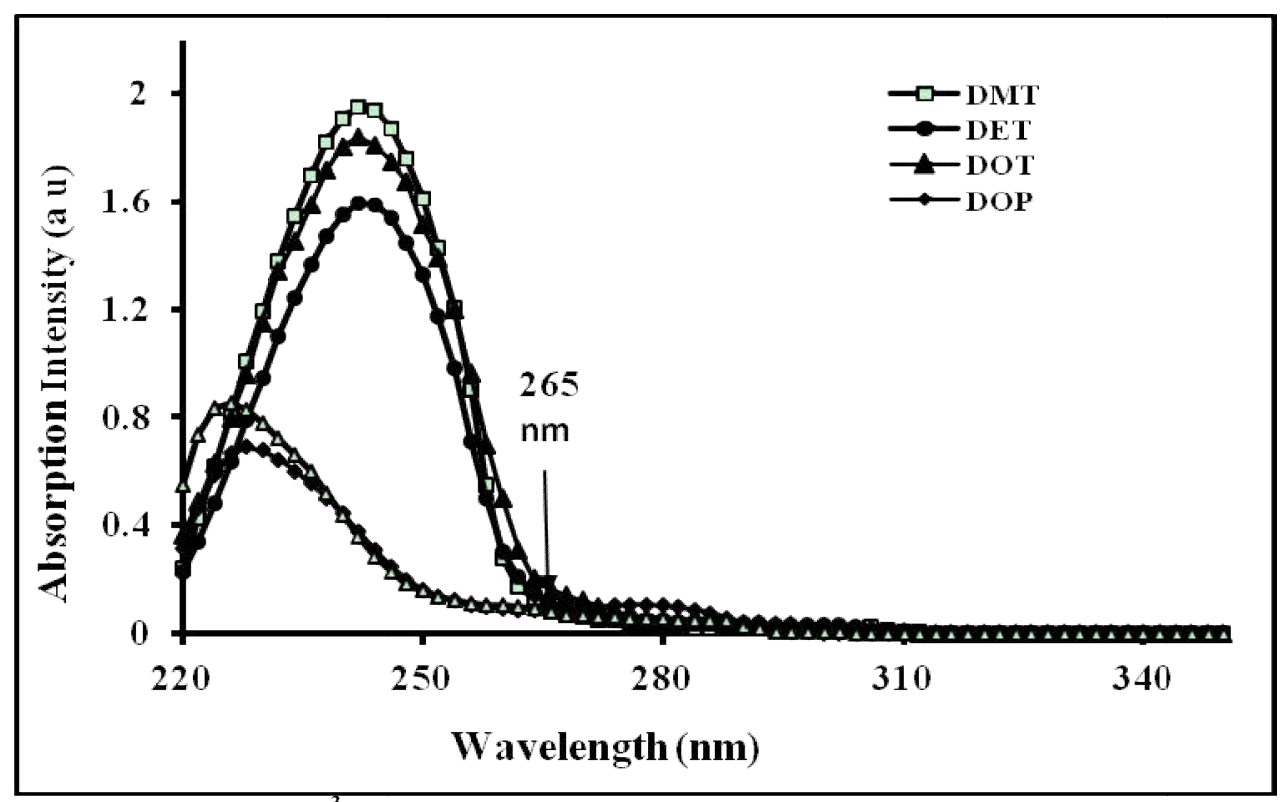

Fig. 1 Absorption spectra of $\left(1 \times 10^{-3} \mathrm{M}\right)$ solution of dimethyl terephthalate (DMT), diethyl terephthalate (DET), dioctyl terephthalate (DOT), dibutyl phthalate (DBP) and dioctyl phthalate (DOP).

In order to evaluate the optical properties of the PETOS system, absorption spectra of the irradiated and non-irradiated polymer in solution have been collected in the range of UV-vis. The spectra provide information about absorption of chromophoric groups present in the structure of photoinitiators and possibility of their excitation upon UV. All prepared specimens were UV-irradiated and both absorption and emission (fluorescence) spectra have been collected immediately after exposure. Excitation of the PETOS chromophore at $265 \mathrm{~nm}$, showed an absorption band with a maxima at $278 \mathrm{~nm}$, and are due to the $\pi, \pi^{*}$ transition in aromatic rings.

The increase in irradiation times of pure PETOS film, showed a gradual increase in the intensity of the absorption spectra as well as a small change in the shape of the spectra, as shown in Fig. 2. The changes that are observed in the absorption spectra are much more important when irradiation is carried out in the presence of air. It was observed that the changes in the absorption spectra of irradiated pure polymer after exposure to UV are insignificant indicating that the formation of products with chromophore group resulted from the photodegradation of polymeric chains. The slight increase in absorbance in the whole
UV-vis region was caused by some photoreactions occurring in the polymer, mainly photo oxidative degradation leading to formation of new type of carbonyl groups and unsaturated bonds.

The effects of irradiation for $180 \mathrm{~min}$ for blended PETOS solid films with $4.0 \%$ of dimethyl terephthalate, diethyl terephthalate, dibutyl phthalate, dioctyl phthalate and dioctyl terephthalate are shown in Fig. 3. Irradiation of blended PETOS with phthalate and terephthalate plasticizers caused a change in the shape and position of the main absorption spectrum as well as a gradual decrease in the absorption spectra with appearance of a small absorption structure at longer wavelength at (345-400 nm) which indicates the formation of new chemical compounds that result from the photodegradation of polymeric chromophores. These new photo-products may absorb radiation at different region from that of the polymer.

The $265 \mathrm{~nm}$ UV light energy has sufficient energy to cleave the bond in the polymeric chains with production of free radicals [2]. The efficiency of the photo-oxidation process is accelerated in presence of atmospheric oxygen, which led to the formation of oxyradicals [27, 28].

As can be seen from Fig. 3, a small increase in the 


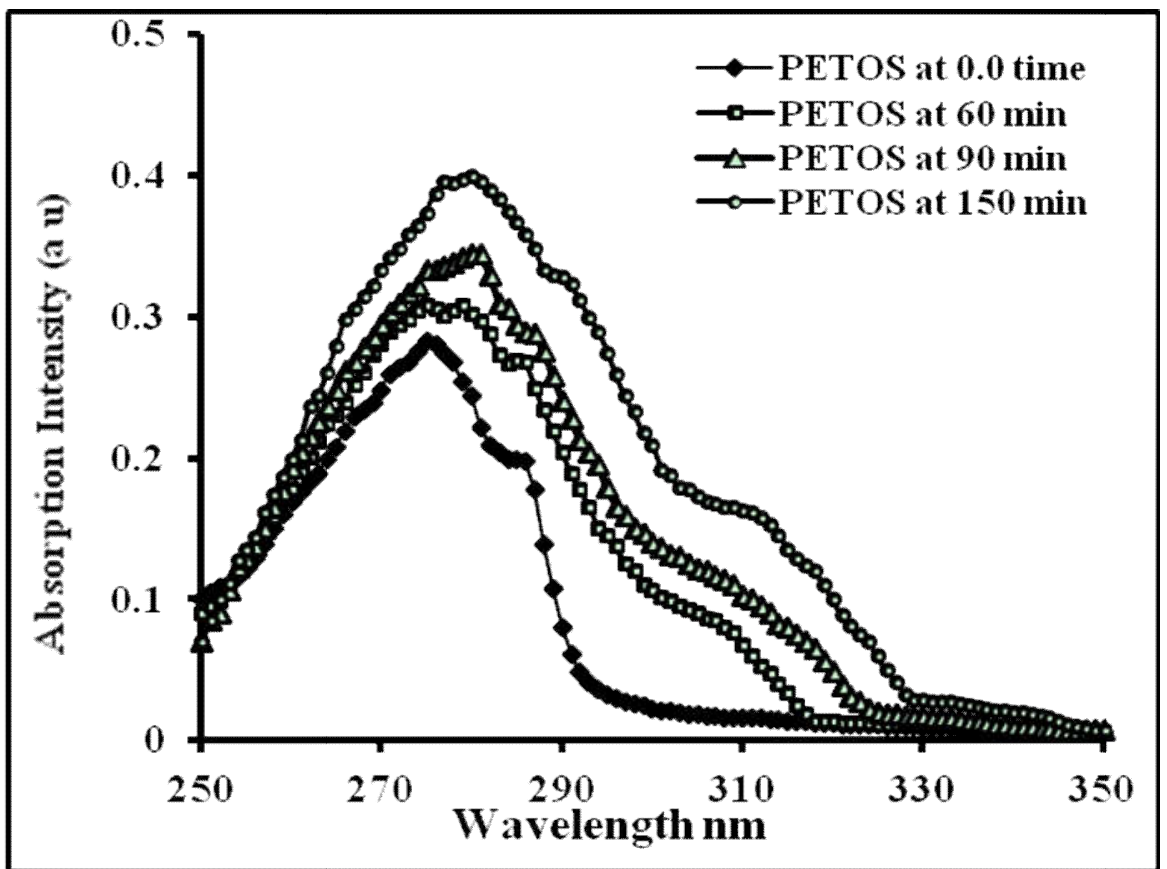

Fig. 2 UV-absorption spectra of, non-irradiated and irradiated for PETOS film at different intervals of irradiation time at $\left(\lambda_{\mathrm{ext}}=265 \mathrm{~nm}\right)$.

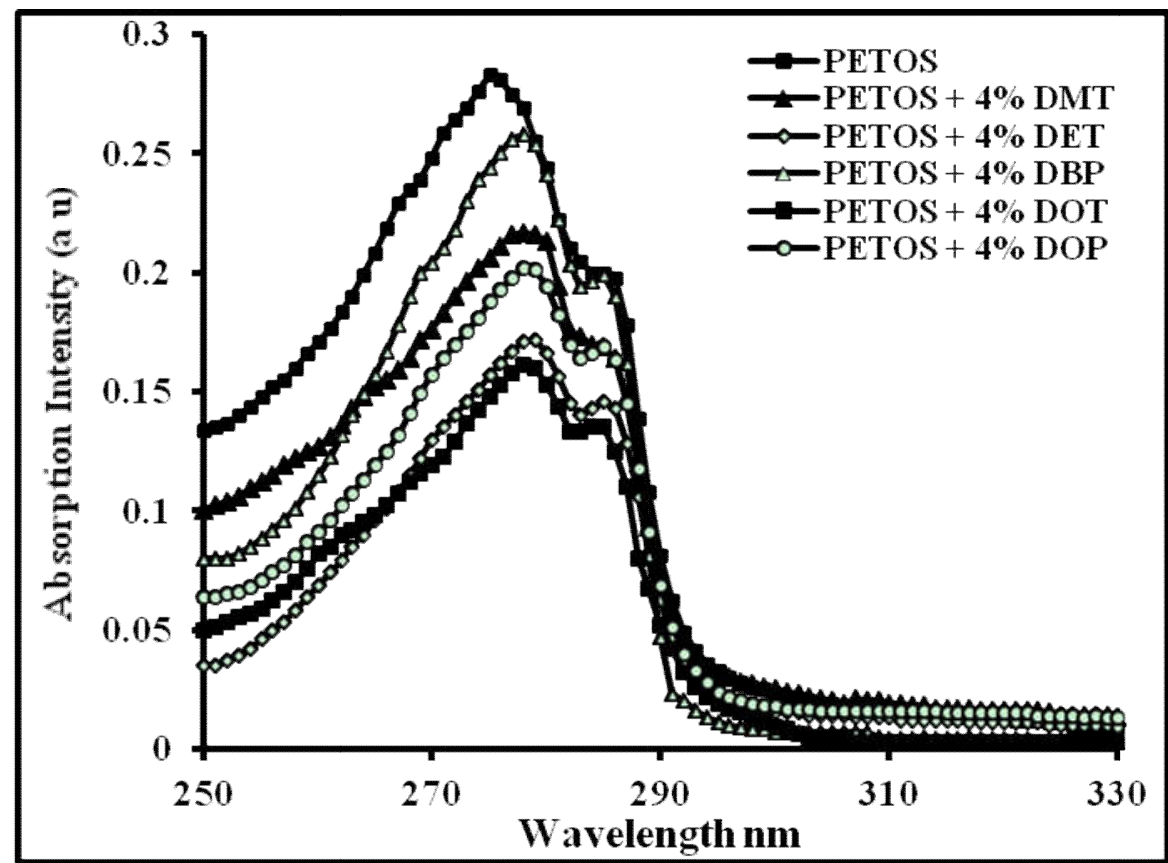

Fig. 3 Effect of added phthalate and terephthalate plasticizers on the intensity of absorption of poly (4-ethoxystyrene) in solid films at irradiation time $=180 \mathrm{~min}$, and at $\left(\lambda_{\text {exc }}=265 \mathrm{~nm}\right)$.

intensity of absorption of a new band at longer wavelength (296-330 nm) was observed. This band has no clear maxima, and appears in the irradiated plasticized polymer films. This may indicate that the photodegradation and photo-oxidation processes of irradiated PETOS films are enhanced in presence of phthalate and terephthalate plasticizers. Irradiated polystyrene films showed absorption by photoproducts at about $350 \mathrm{~nm}$ during photodegradation processes [29, 30]. The 
photoproducts resulting from the reaction were involving benzene-ring opening photo-oxidation in polystyrene chromophores [31].

\subsection{Effect of Irradiation Time and Concentration on} Fluorescence Intensity of Pure Poly (4-Ethoxystyrene) (PETOS) at $\left(\lambda_{\text {exc }}=265 \mathrm{~nm}\right)$

The effect of change concentration of PETOS in (DCE) solvent on the stability of polymer when irradiated at different intervals of time studied at room temperature is presented in Fig. 4.

As can be noticed from Fig. 4, irradiation of PETOS with UV light energy showed a marked decrease in the intensity of excimer fluorescence. The increase in the irradiated polymer concentration caused a larger decrease in fluorescence intensity and change in the shape of the fluorescence spectrum. Also, it was noticed that the intensity of monomer fluorescence band (280-315 nm) was decreased in comparison with the intensity of excimer fluorescence band (315-430 nm) upon irradiation on the polymeric solution. This was confirmed by plotting the ratio of $\left(I_{\mathrm{M}}^{0} / I_{\mathrm{M}}\right)$ against the time of irradiation as shown in Fig. 5 .

As can be observed from Fig. 5, as the molarity of the polymer increases, the efficiency of quenching of monomer fluorescence decreases. This is due to the decrease of polymer chromophores by decreasing of the polymer concentration. The same observations were obtained in the quenching of excimer emission as can be observed from Fig. 4 .

The rate of quenching of polymer fluorescence in solid films is slower than that in solution. This can be explained as follow: the lower mobility of polymer chromophores is in polymer matrix, the diffusion of polymer chromophores is restricted, contrary to solution where movement of chromophores is less restricted. Also the diffusion of atmospheric oxygen is more limited in the film than that in solution, then; the efficiency of quenching of excited states is lower than that in solid films [32].
3.3 Effect of UV-Irradiation Time on Fluorescence Intensity of Pure and Blended Poly (4-Ethoxystyrene) Films with DMT, DOT and DOP Plasticizers at $\left(\lambda_{e x c}=\right.$ $265 \mathrm{~nm})$

The fluorescence spectra were obtained for pure PETOS films, photo irradiated for $(0.0-150 \mathrm{~min})$ at $298 \mathrm{~K}$ and in presence of air. Irradiation of solid films of pure polymer was accompanied by decrease in the intensity of the fluorescence band as well as a small red shift in the $\lambda_{\max }$ of the excimer fluorescence band. These changes may be attributed to the photodegradation of polymeric chains through chain scissions, and the formation of conjugated double bonds along the polymer chain during the photodegradation by hydrogen abstraction process [21, 33].

The red shift in the excimer fluorescence band of the irradiated poly (4-ethoxystyrene) film is in good agreement with that reported with irradiated polystyrene and substituted polystyrene solid films [8,28].

Tovborg and Kops [21] pointed out that quenching of polymeric emission might be attributed to the energy transportation of the oxides formed by the photo-oxidation of polymeric chromophores, or to the quenching effect of the formed peroxide formed during UV-irradiation.

In order to estimate the influence of blending of PETOS solid films with dioctyl terephthalate (DOT), dibutyl phthalate (DBP), and dimethyl terephthalate (DMT), the fluorescence spectra of pure and blended PEOXS films were recorded immediately after each irradiation time and are presented in Fig. 6.

The blending of polymer film with $(4.0 \%$ DOP and $4.0 \%$ DBP and 4\% DMT), shows only excimer and monomer fluorescence bands and no exciplex emission was observed upon the increase in the percentage off added plasticizers. Most likely, the formed energy transfer complex formed between the polymer chromophore and the plasticizer molecule is not stable enough to give exciplex fluorescence emission. 


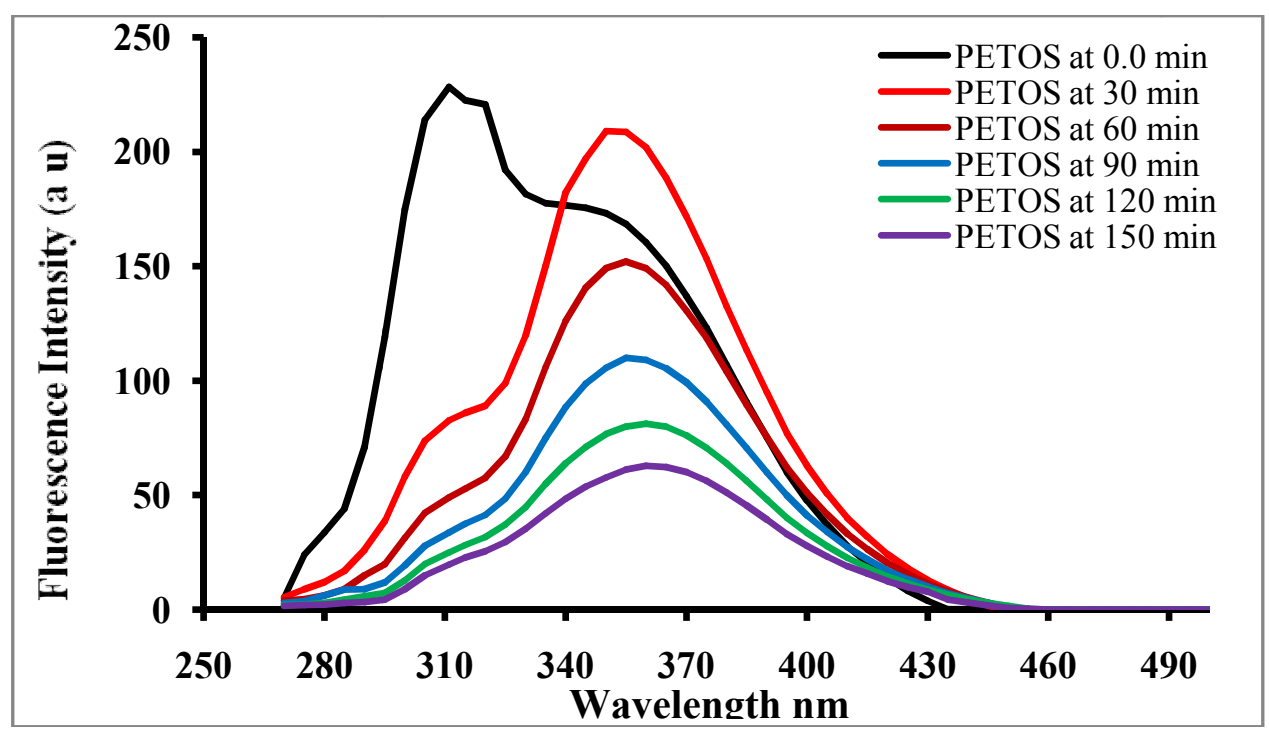

(a)

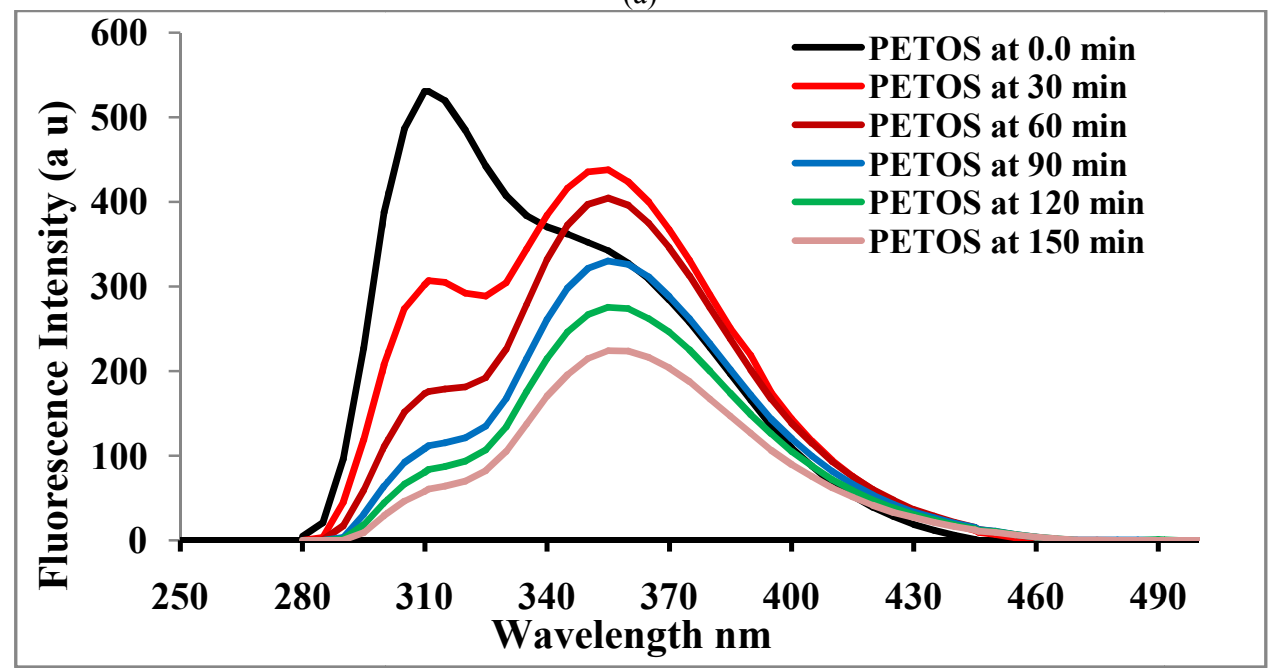

(b)

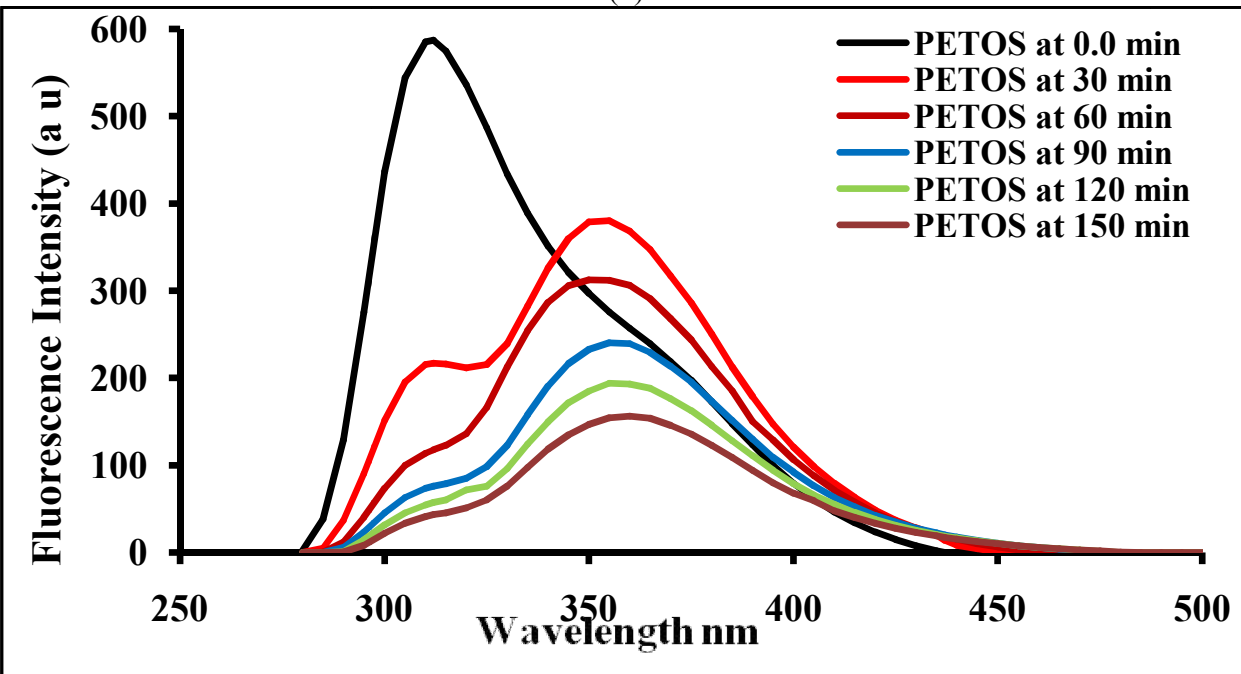

(c)

Fig. 4 Effect of irradiation times and concentration on the excimer fluorescence intensity of PETOS at, (a): $1 \times 10^{-3} \mathrm{M},(\mathrm{b})$ : $5.0 \times 10^{-4} \mathrm{M}$ and $(\mathrm{c}): 1 \times 10^{-4} \mathrm{M}$, at $\left(\lambda_{\mathrm{exc}}=265 \mathrm{~nm}\right)$. 


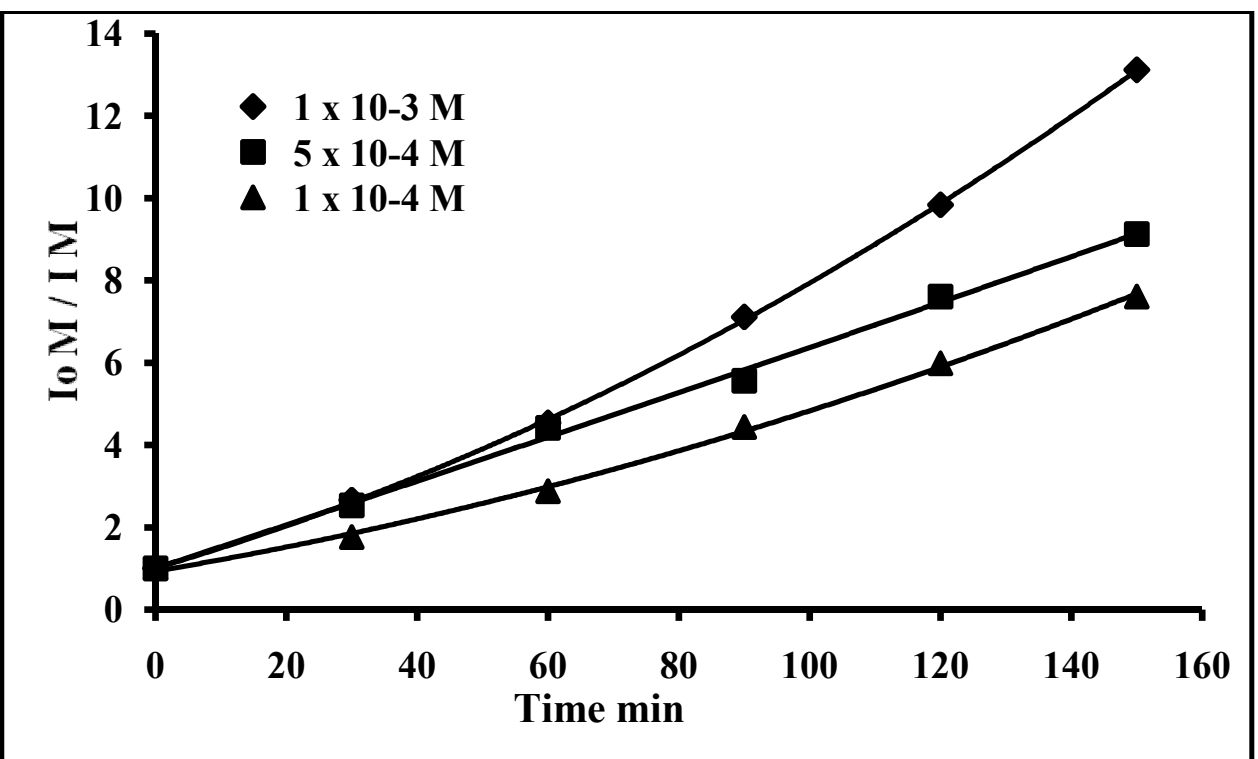

Fig. 5 Effect of irradiation time on the intensity of monomer fluorescence of pure PETOS solid films at $\left(\lambda_{\text {exc }}=265 \mathrm{~nm}\right)$.

As can be seen from Fig. 6, the blended poly (4-ethoxystyrene) films have slightly some modification to that of pure film, where the quenching efficiency in the intensity of the fluorescence band was increased by the increase in irradiation time (0.0-150 $\mathrm{min})$. It was also noticed a small change in the shape of the fluorescence spectra, a small red shift and the increase in the fluorescence intensity of a new broad band without clear maxima at longer wavelength (342-378 nm), as clearly seen by blending with DOT plasticizer. This finding is with full agreement with that obtained with irradiated poly (4-methylstyrene) [34]. The formation of new fluorescence broad band at longer wavelength, was found to increase its intensity with the increase of irradiation time, and may be attributed to the formation of excited complex from the excited polymer chromophores and the ground state terephthalate molecules [35].

To compare the UV influence on different samples of PETOS at different concentrations, the relative change of fluorescence intensity has been calculated according to the following formula.

$$
\Delta I_{\text {arb }}=\frac{I_{\mathrm{o}}-I_{\mathrm{t}}}{I_{\mathrm{o}}}
$$

where $I_{\mathrm{o}}$ and $I_{\mathrm{t}}$ are fluorescence intensity of polymeric films before and after $t$ time of irradiation, respectively.

It is well known that fluorescence measurements provide interesting information on the progress of photodegradation irradiated plasticized poly (4-ethoxystyrene) films. In order to facilitate the quantitative comparison of the observed processes, the relative changes in fluorescence intensity were calculated according to Eq. (1). The results are presented in Fig. 7.

As can be seen, blending with DBP is characterized by more efficacious fluorescence decay in comparison to that obtained by blending with DOT and DMT. In general phthalate plasticizers showed a higher efficiency of fluorescence quenching than that obtained by terephthalate plasticizers. Probably energy transfer processes occur as a result of intermolecular interactions between photoinitiators in excited state and the polymer in ground state. Moreover, irradiation of polymeric chromophores with UV-radiation initiates the formation of free radicals and in presence of atmospheric oxygen, peroxy radical can be formed in the polymeric matrix. Peroxy radicals can abstract hydrogen atom from the polymeric chromophores which initiates chain scission. The gradual increase in the formation of new fluorescence broad band with increasing of irradiation time and the decrease in the 

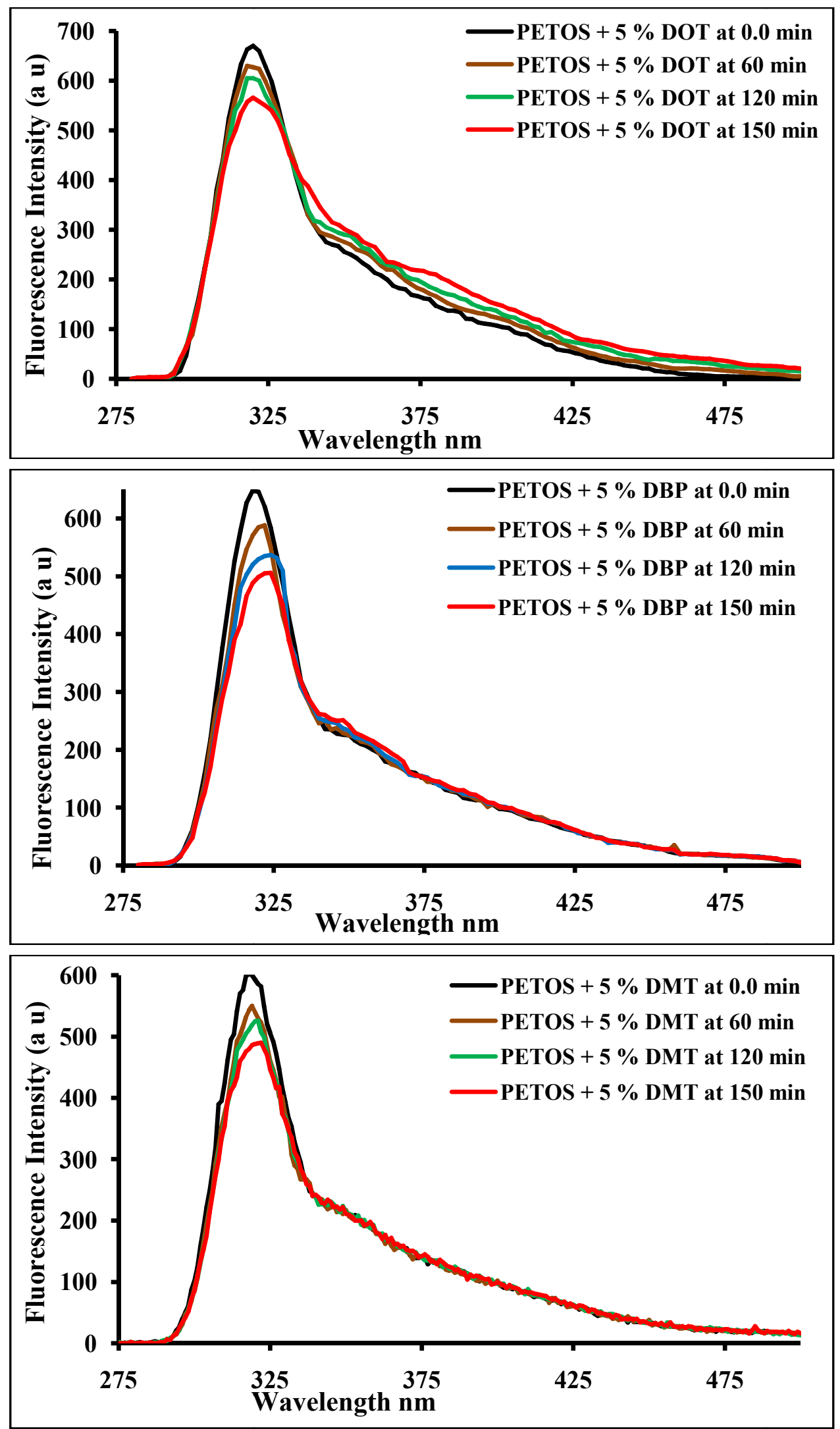

Fig. 6 Effect of added phthalate and terephthalate plasticizers on the fluorescence intensity of irradiated PETOS at $\left(\lambda_{\text {exc }}=\right.$ $265 \mathrm{~nm})$. 


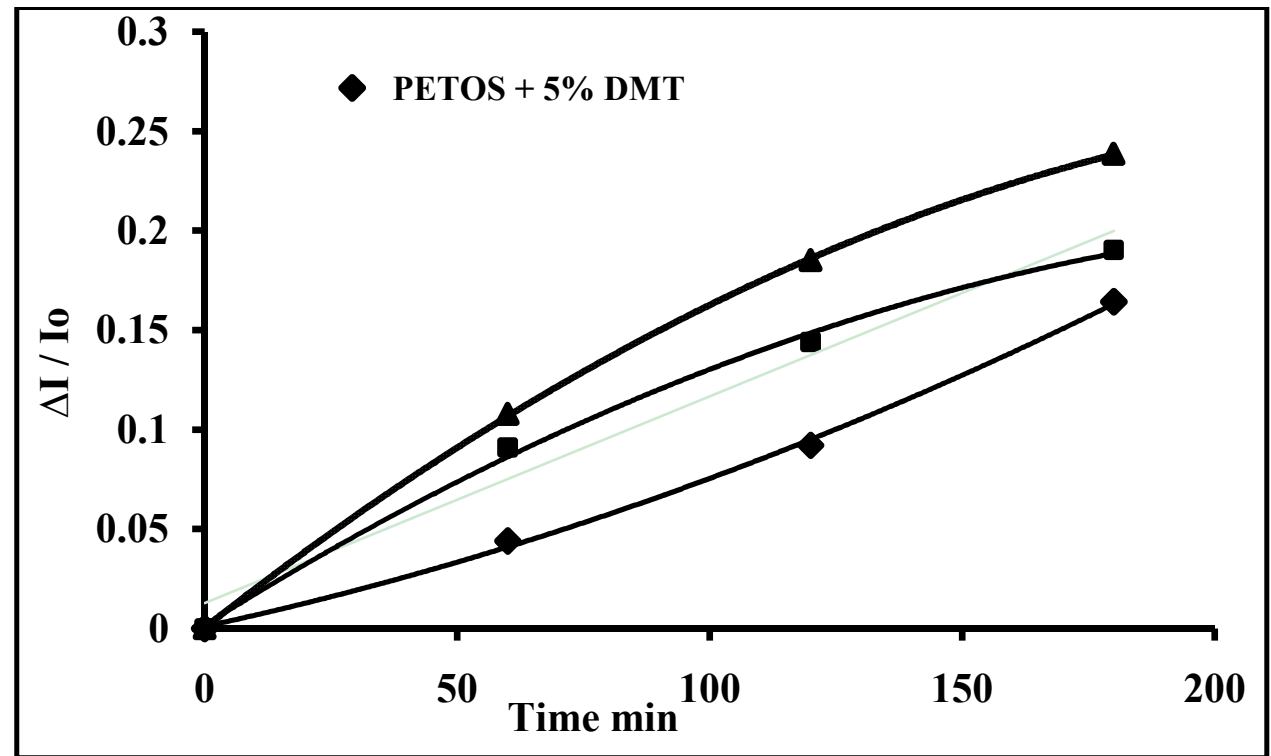

Fig. 7 Relative changes in fluorescence intensity of Irradiated pure and plasticized PETOS solid films with 5.0\% DMT, DOT and DBP at $\left(\lambda_{\mathrm{exc}}=265 \mathrm{~nm}\right)$.

intensity of the excimer fluorescence band occurs as a result of the formation of new compounds from the photo-oxidation and photodegradation processes of irradiated polymeric films, indicating the possibility of formation of polyene unit structures and possibly other oxygen containing compounds.

Based on the work of Geuskens et al. [19] relevant to photodegradation of PS, the fluorescence bands of 362,425 and $477 \mathrm{~nm}$ corresponded to the formation of new photo product which was identified to be polyene unit structure, and were defined by $(n=1,2$ and 3$)$ respectively.

\subsection{Kinetics and Mechanism of Photodegradation of Pure and Blended Poly (4-Ethoxystyrene) Solid Film}

The intensity of the fluorescence bands was found to decrease by the increase in irradiation time and by blending with phthalate and terephthalate plasticizers. The decrease in the efficiency of fluorescence quenching of polymeric film by the increase in the amount of added plasticizers and by the increase in irradiation times at room temperature can be followed by applying Al Ani-Hawi equation [8]. The ratio of $\left\{I_{\mathrm{EX}}^{\mathrm{0}} / I_{\mathrm{EX}}\right\}$ was found to increase by the increase in irradiation time to polymeric film. $\left\{I_{\mathrm{EX}}^{\mathrm{o}}\right\}$ is the intensity of excimer fluorescence of pure or blended polymer at zero time of irradiation, whereas, $\left.\left\{I_{\mathrm{EX}}\right\}\right\}$ is the intensity of excimer emission of pure or blended polymer at different intervals of exposure time.

$$
\left\{\frac{I_{\mathrm{EX}}^{\mathrm{o}}}{\left.I_{\mathrm{EX} *}\right\}}\right\}=1+\left\{\left(k_{\mathrm{PQ}}^{\prime}\right)(A)\right\}(t)
$$

where $(A)=$ number of (photons/s) absorbed by polymeric chromophores, $t=$ time of irradiation in $\mathrm{s}$, $k_{\mathrm{PQ}}^{\prime}=$ rate constant.

And,

$$
\left\{\frac{I_{\mathrm{EX}}^{o}}{\left.I_{\mathrm{EX}}\right\}}\right\}=1+\left\{\left(k_{\mathrm{PQ}}\right)\right\}(t)
$$

where the quenching rate constant $\left(k_{\mathrm{PQ}}\right)$ is equal to:

$$
k_{\mathrm{PQ}}=\left\{\left(k_{\mathrm{PQ}}^{\prime}\right)(A)\right\}
$$

In the photo-quenching processes, if we assume that the number of photons released from the light source and absorbed by polymer chromophores is constant (A), then, according to Eq. (3), $\left\{I_{\mathrm{EX}}^{0} / I_{\left.\mathrm{EX}^{*}\right\}}\right.$-values were plotted against time of irradiations $(t)$. From the plots, the photo-quenching rate constant $\left(k_{\mathrm{PQ}}\right)$ values and $\left\{I_{\mathrm{EX}}^{0} / I_{\mathrm{EX}}\right\}$-ratios were calculated and were used to estimate the efficiency of photo quenching and photodegradation processes for pure and blended polymer. The plots of the ratio of excimer fluorescence $\left\{I_{\mathrm{EX} *}^{\mathrm{o}} / I_{\mathrm{EX}}\right\}$ against the different irradiation time of blended poly (4-ethoxystyrene) films with 5\%, of DMT, DBP and DOT are presented in Fig. 8. 
As can be seen from Fig. 8, the increase in the time of irradiation caused an increase in the photo quenching ratio in the photo quenching $\left(I^{o} \mathrm{EX} / I_{\mathrm{EX}}\right)$ as well as an increase in the photo quenching rate constant $\left(k_{P Q}\right)$ values, and found to depend upon the structure of the plasticizer molecules. Phthalate plasticizers showed a lower efficiency of photo-quenching in comparison with that obtained with terephthalate plasticizers.

The corresponding fluorescence photo-quenching rate constant values $\left(k_{\mathrm{PQ}}\right)$ and the efficiency of photo-quenching ratio $\left(I^{o}{ }_{\mathrm{EX}} / I_{\mathrm{EX}}\right)$ of blended PETOS solid films are shown in Table 1.

As can be seen from Table 1, the photo quenching rate constant $\left(k_{\mathrm{PQ}}\right)$ increased with the increase in the molar mass of the used plasticizers and terephthalate gave lower values of $\left(k_{\mathrm{PQ}}\right)$ in comparison with the phthalate plasticizer.

It was reported that the photo-degradation mechanism of PS chromophores in solid films was dependent upon the rate of oxygen diffusion into the polymer matrix, and on the formation of charge transfer complexes between polymer chromophores and oxygen molecules [3, 7]. The rate of photo-oxidation is dependent upon the reactivity of oxygen molecules with the formed radicals in polymeric matrix. A combination of these formed macro-radicals may lead to cross-linking [36]. A more detailed discussion on the processes involved in the oxidative degradation in polymeric chains, has been reported by Rabek [11, 12]. The photo-oxidative degradation in PS chromophores is free radical chain mechanism which occurs when polymeric chains are exposed to UV-radiations in presence of air [37].

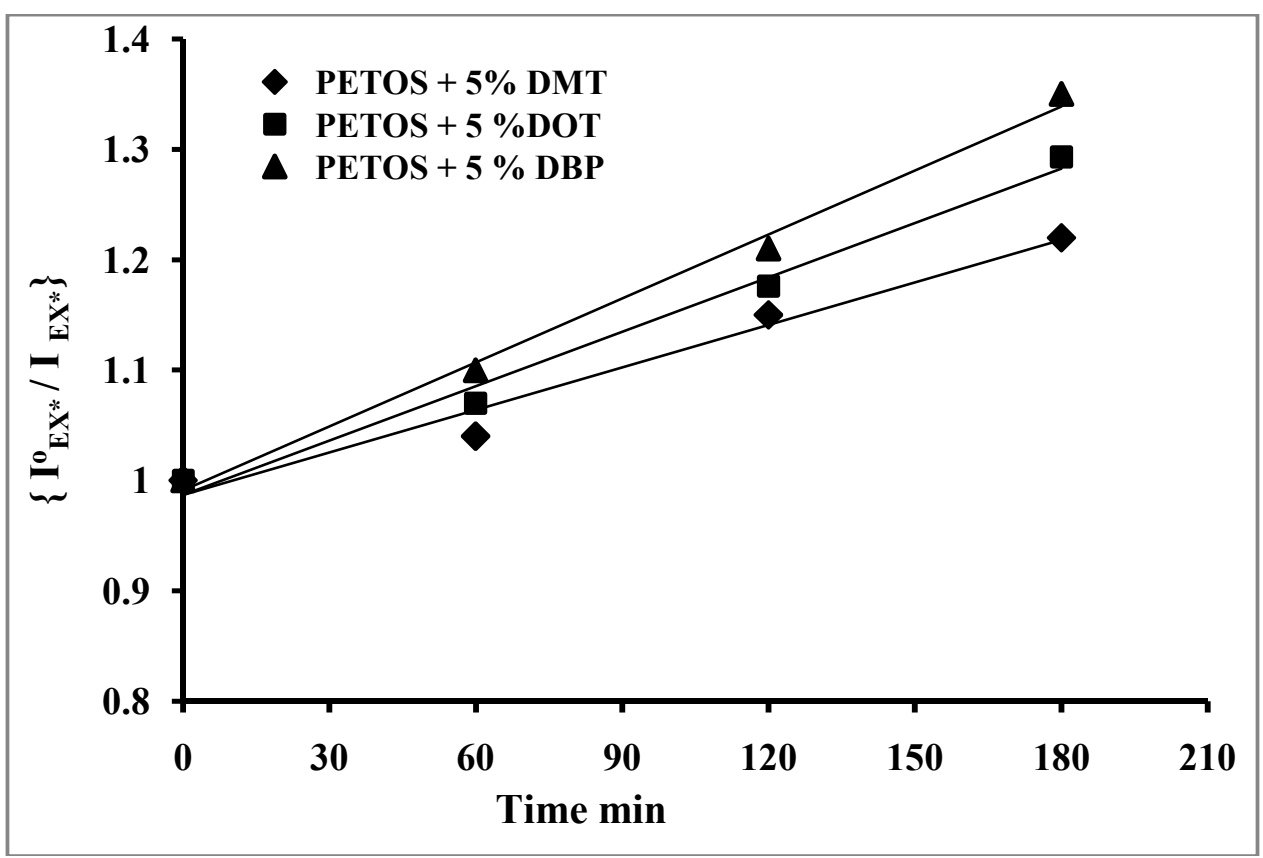

Fig. 8 Plot of $\left(I_{\mathrm{EX}}{ }_{\mathrm{EXX}}\right)$ fluorescence ratio of non-plasticized and plasticized (PETOS) with DMT, DOT and DBP plasticizers plotted against exposure time (0-180) $\mathrm{min}$.

Table 1 Relative intensities of the ratio $\left\{I_{\mathrm{EX}^{*}}^{0} / I_{\mathrm{EX}}{ }^{*}\right\}$ for intensities of excimer fluorescence bands and excimer fluorescence photo quenching rate constant values $\left(k_{\mathrm{PQ}}\right)$ of irradiated pure and blended PETOS solid films.

\begin{tabular}{llllll}
\hline (Emiss.) $(\mathrm{nm}) \lambda$ & Plasticizer (\%) & Time (min) & $\mathrm{R}^{2}$ & $\left\{\mathrm{I}_{\mathrm{EX}}^{\mathrm{o}} / \mathrm{I}_{\mathrm{EX}}\right\}$ & $k_{\mathrm{PQ}}$ \\
\hline 218 & PETOS & 180 & 0.991 & 1.193 & 0.0019 \\
219 & PETOS + 5\% DMT & 180 & 0.995 & 1.221 & 0.0016 \\
221 & PETOS + 5\% DOT & 180 & 0.987 & 1.293 & 0.0012 \\
224 & PETOS + 5\% DBP & 180 & 0.987 & 1352 & \\
\hline
\end{tabular}


If we consider the photo-quenching rate constant $\left(k_{\mathrm{PQ}}\right)$ is an indication of efficiency of the photodegradation of blended polymeric chromophores, PETOS films showed an increase in the efficiency of photodegradation process, with the increase in irradiation time. Another factor is that these plasticizers showed a small absorption in the region of absorption of polystyrene, thus they may act as UV-absorbers [38].

From the data obtained for irradiated pure and blended PETOS solid films, we can notice that the photostability of polymeric chromophores is similar to that found in the irradiation of polystyrene and other substituted polystyrene. This fact can be explained as phenyl ring substitution (as an inert group) in the para position of the styrene monomer may increases the photostability of polymer towards irradiation. On the other hand, the methoxy group substitutions make the hydrogen abstracting process during the irradiation process as a difficult process $[39,40]$.

\subsection{FT-IR Spectra for Non-irradiated and Irradiated Pure and Blended PETOS Solid Films}

The effects of added phthalate and terephthalate plasticizers on the stability of irradiated PETOS films are further supported by FT-IR spectra analysis of irradiated pure and blended PETOS films with $10 \%$ DBP, $10 \%$ DOP, $10 \%$ DMT, 10\% DET and 10\% DOT for (3.0 hours) and were measured at exciting radiation of $265 \mathrm{~nm}$. The $\%$ transmittance of polymer solid films was measured at the range of wavenumber from $\left(4,000-500 \mathrm{~cm}^{-1}\right)$ at $298 \mathrm{~K}$ and were recorder immediately before and after irradiation.

The FT-IR spectra of irradiated and non-irradiated pure PETOS solid films are shown in Fig. 9a. The FT IR spectra of blended PEOXS with dibutyl phthalate plasticizer (DBP) and that for dioctyl phthalate plasticizer (DOP) are shown in Figs. 9b and 9c respectively.

The FT IR spectra of irradiated and non-irradiated blended PETOS solid films with dimethyl terephthalate plasticizer and blended with diethyl terephthalate plasticizer and blended with dioctyl terephthalate plasticizer are shown in Figs. 10a, 10b and $10 \mathrm{c}$ respectively.

As can be noticed from Figs. 9 and 10, the irradiated polymer solid film and that of blended PETOS solid films, showed an increase in the intensity of transmittance of many bands, decrease in the intensity of other bands as well as disappearance of some bands upon irradiation of blended polymer solid films.

In an earlier study, it has been reported that irradiation of polystyrene solid films resulted in changes in many bands in the FT IR spectra [9], and also was noticed in the irradiated pure and blended poly (fluoro styrene) isomers with phthalate and terephthalate plasticizers in solid films $[24,25]$. The same observation was noticed in the irradiation of poly (4-vinyl biphenyl) solid films [41].

It was noted that the most demonstrated trend is the increase of the absorbance bands at $\left(3,800-3,000 \mathrm{~cm}^{-1}\right)$, and by the formation of new absorption bands corresponding to new compounds resulting from the polymer chains photodegradation in different regions of the spectra. The following bands are found to refer to the following functional groups, in which several authors reported the formation of absorption bands in the range $\left(3,600-3,400 \mathrm{~cm}^{-1}\right)$ is attributed to formation of the hydroxyl group. They are formed only in the presence of air (oxygen) and are probably due to oxidized benzene rings in polystyrene macromolecules [11].

As can be observed from Figs. 9 and 10, modifications occur in different bands in the FT IR spectra of irradiated pure and blended PETOS films. It has been reported that the following bands in the range $\left(3,600-3,400 \mathrm{~cm}^{-1}\right)$, are attributed to formation of the hydroxyl group. They are formed only in the presence of air (oxygen) and are probably due to oxidized benzene rings in polystyrene macromolecules, and can indicate the increase in the 

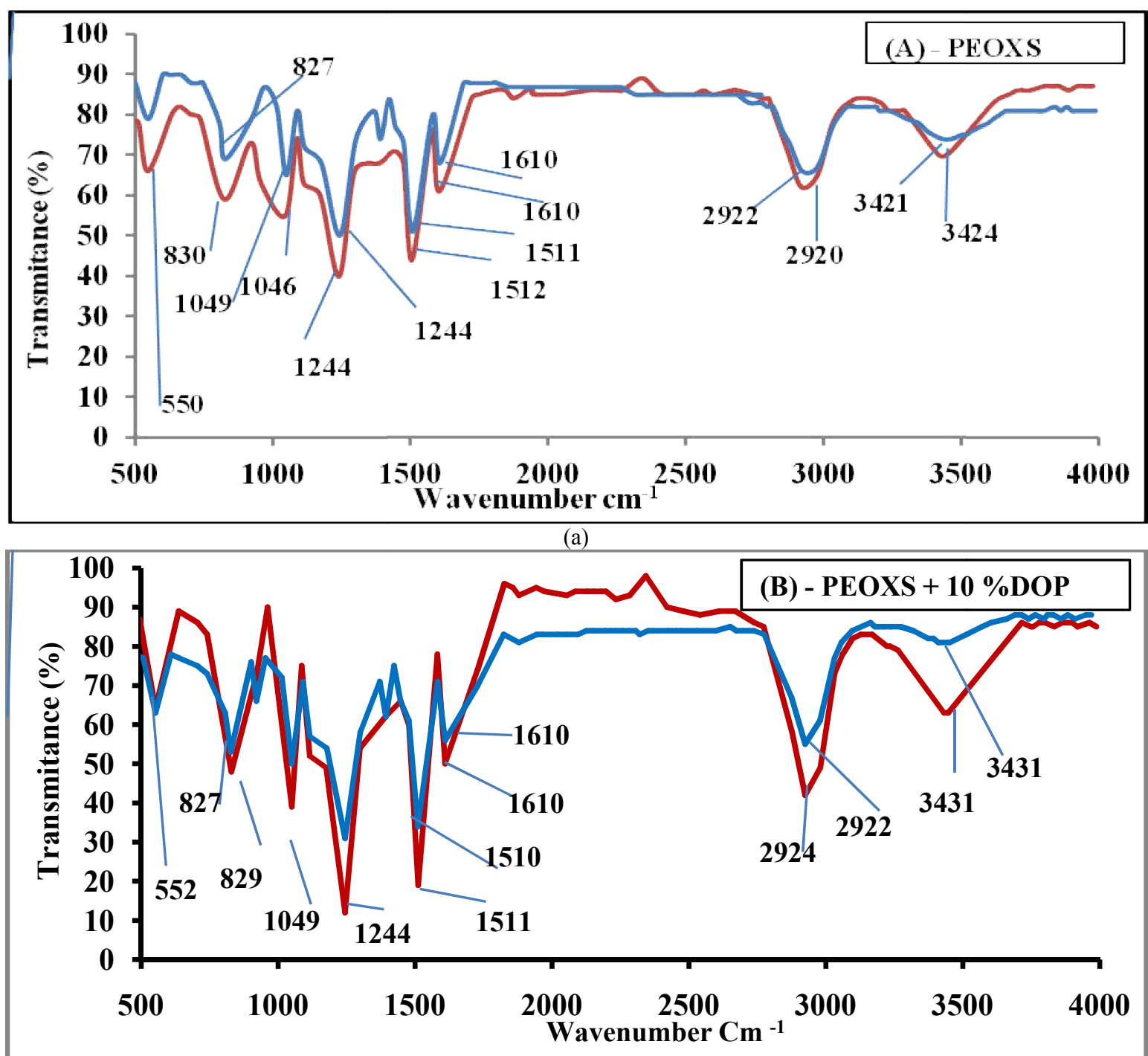

(b)

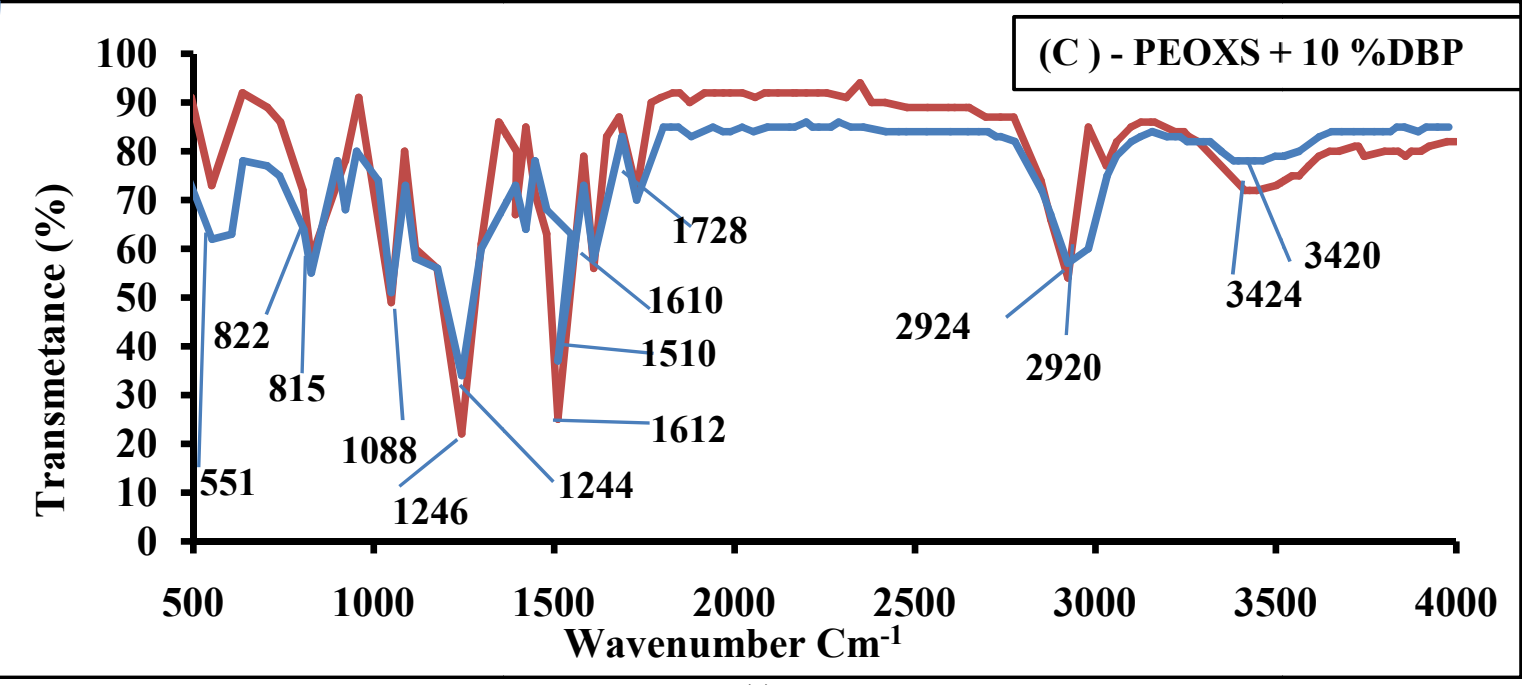

(c)

Fig. 9 FT-IR spectra of non-irradiated (blue line), (a): PEOXS solid film, and irradiated (red line); for (3.0 hours) of blended PEOXS solid film with; (b): PEOXS + 10\% DOP; (c): PEOXS + 10\% DBP at $\left(\lambda_{\text {ext }}=265\right.$ nm). 

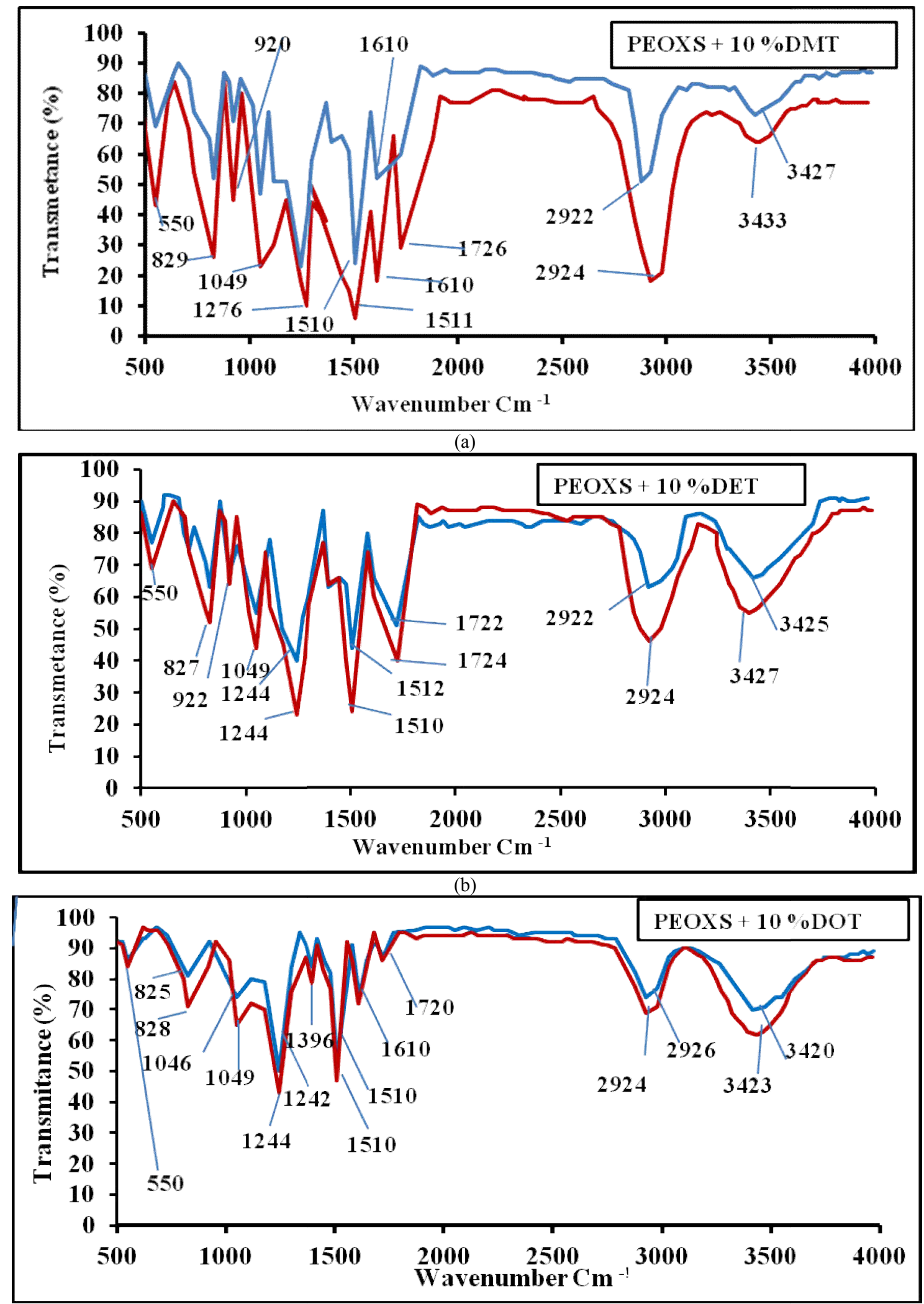

(c)

Fig. 10 FT-IR spectra of non-irradiated blended PEOXS solid films (blue line) and irradiated blended PEOXS (red line) for (3.0 hours) with (a): PEOXS + 10\% DMT, (b): PEOXS + 10\% DET and (c): PEOXS + 10\% DOT, at $\left(\lambda_{\mathrm{ext}}=265 \mathrm{~nm}\right)$. 
aromacity of the sample by increase in irradiation time [11]. The FT IR bands in the range of $(3,100-2,800$ $\mathrm{cm}^{-1}$ ), refer to the formation of $\mathrm{C}-\mathrm{H}$ stretching vibration in the aliphatic chain, and in the aromatic rings. The FT-IR bands in the range of $(1,700-1,600$ $\left.\mathrm{cm}^{-1}\right)$ are assigned to a $(\mathrm{C}=\mathrm{O})$ vibration [27]. In the infrared spectra of the photooxidized PETOS films, we noticed the formation of $825 \mathrm{~cm}^{-1}$ band, which was attributed to conjugated double bond sequences in the main polymer chain [42, 43], while the bands in the range of $\left(1,400-600 \mathrm{~cm}^{-1}\right)$, are considered to be a deformation vibration region. The chemical changers during irradiation of polymer solid films were assessed by FT IR spectra. These changes in the bands are corresponding to the photodegradation and to the photo-oxidation of polymeric chains [25]. It was observed that the most demonstrated trend was the increase of the increase in the intensity of the absorption band upon irradiation of polymeric films in the range $\left(3,750-3,200 \mathrm{~cm}^{-1}\right)$. Several authors have reported that the bands in this region are attributed to the formation of hydroxyl group that results from the degradation of polymeric chromophores in presence of air and are probably due to the oxidizing benzene rings and to the decrease in the aromacity in polystyrene chromophores [13, 18]. They reported three cases of benzene ring photo-oxidation: formation of benzyl acetophenone chromophores; acetophenone structures; and conjugated double bonds. The same observation was noticed in the irradiation of other substituted polystyrenes in solid films $[25,26]$.

As can be seen from Figs. 9a-9c) the FT IR band in the range of $\left(3,100-2,750 \mathrm{~cm}^{-1}\right)$ showed an increase in the intensity upon irradiations of pure polymer film or irradiation of the blended PETOS solid films with dibutyl phthalate or dioctyl phthalate and is assigned to a $(\mathrm{C}=\mathrm{H})$ stretching vibration in the aliphatic chain, and in aromatic ring [9]. It also showed an increase in the absorption intensity of the bands at $(1,700-1,400$ $\left.\mathrm{cm}^{-1}\right)$ upon irradiation of polymeric films. These band are assigned to a $(\mathrm{C}=\mathrm{O})$ vibration [27]. An increase in the intensity of the FT IR band at $\left(820 \mathrm{~cm}^{-1}\right)$ was noticed in the irradiation of pure or blended polymer films, which was attributed to the conjugated double bond sequence in the main polymer chain [43].

The same observations of decrease or increase of red shift in the FT IR bands were observed in Figs. $10 \mathrm{a}, 10 \mathrm{~b}$ and $10 \mathrm{c}$ which show the irradiations effect for three hours on blended PETOS films with dimethyl terephthalate, diethyl terephthalate and dioctyl terephthalate respectively. These observations were summarized in Tables 2 and 3.

As can be notched from Tables 2 and 3, the increase in the intensity of FT IR bands and the small red shift in other bands upon blending with phthalate and terephthalate plasticizers, can give good indication of acceleration of photodegradation of polymeric chains, and the photo-oxidation of polymeric chains in presence of air.

The data reported in Figs. 9 and 10, and Tables 2 and 3 for the irradiated pure and blended polymer, permit characterization these modifications in the following points:

At the high region of the FT IR spectra, a noticeable increase in the absorption of the $3,422 \mathrm{~cm}^{-1}$ band is observed in irradiated blended polymer films, on the other hand a small increase in the absorption of many bands in the irradiated pure polymer film. Which can be ascribed to the associated carboxylic acid group [15, 44]?

The absorption band between 2,960 $\mathrm{cm}^{-1}$ and 2,840 $\mathrm{cm}^{-1}$, centered at about $2,920 \mathrm{~cm}^{-1}$, is assigned to the $(\mathrm{C}-\mathrm{H})$, stretching vibration of benzene, and found to increase its intensity with irradiation of blended polymer. Such observation suggests that photodegradation of PETOS involves the oxidation of benzene ring [27]. 
Table 2 FT IR band position of pure and blended PETOS solid films, before and after (0.0 hr and 3.0 hrs) irradiation at $\left(\lambda_{\text {ext }}=265 \mathrm{~nm}\right)$.

\begin{tabular}{|c|c|c|c|c|}
\hline Polymer & $\begin{array}{l}\text { Band }\left(\mathrm{cm}^{-1}\right) \\
(0.0 \mathrm{~min})\end{array}$ & $\begin{array}{l}\text { Band }\left(\mathrm{cm}^{-1}\right) \\
(120 \mathrm{~min})\end{array}$ & Type of vibration & Intensity \\
\hline \multirow{8}{*}{ PETOS } & 3,421 & 3,424 & $(\mathrm{O}-\mathrm{H})$ stretching vibration of carboxylic acid & Increasing \\
\hline & 2,922 & 2,920 & $(\mathrm{C}-\mathrm{H})$ stretching vibration of benzene & Increasing \\
\hline & 1,610 & 1,610 & $(\mathrm{C}=\mathrm{C})$ stretching vibration in dines & Increasing \\
\hline & 1,511 & 1,512 & $(\mathrm{C}=\mathrm{O})$ stretching aromatic ketone & Increasing \\
\hline & 1,244 & 1,244 & $(\mathrm{C}-\mathrm{O})$ stretching vibration & Decreasing \\
\hline & 1,046 & 1,046 & (C-O-C) stretching vibration & Increasing \\
\hline & 827 & 830 & Conjugated double bond & Increasing \\
\hline & 550 & 550 & $(\mathrm{C}=\mathrm{C})$ stanching vibration in dines & Increasing \\
\hline \multirow{9}{*}{ PETOS $+10.0 \%$ DOP } & 3,431 & 3,431 & $(\mathrm{O}-\mathrm{H})$ stretching vibration of carboxylic acid & Increasing \\
\hline & 2,924 & 2,922 & $(\mathrm{C}-\mathrm{H})$ stretching vibration of benzene & Increasing \\
\hline & 1,610 & 1,610 & $(\mathrm{C}=\mathrm{C})$ stretching vibration in dines & Increasing \\
\hline & 1,510 & 1,511 & $(\mathrm{C}=\mathrm{O})$ stretching aromatic ketone & Increasing \\
\hline & 1,244 & 1,244 & $(\mathrm{O}-\mathrm{H})$ stanching vibration & Increasing \\
\hline & 1,049 & 1,049 & $(\mathrm{C}=\mathrm{O})$ stanching vibration & Increasing \\
\hline & ------- & 922 & $(=\mathrm{C}-\mathrm{H})$ bending & New band \\
\hline & 827 & 829 & Conjugated double bond & Increasing \\
\hline & 552 & 555 & $(\mathrm{C}=\mathrm{C})$ stanching vibration in dines & Decreasing \\
\hline \multirow{10}{*}{ PETOS $+10.0 \%$ DBP } & 3,420 & 3,423 & $(\mathrm{O}-\mathrm{H})$ stretching vibration of carboxylic acid & Increasing \\
\hline & 2,926 & 2,924 & $(\mathrm{C}-\mathrm{H})$ stretching vibration of benzene & Increasing \\
\hline & 1,728 & 1,728 & $(\mathrm{C}=\mathrm{O})$ stretching vibration & Increasing \\
\hline & 1,610 & 1,610 & $(\mathrm{C}=\mathrm{C})$ stretching vibration in dines & Increasing \\
\hline & 1,510 & 1,510 & $(\mathrm{C}=\mathrm{O})$ stretching aromatic ketone & Increasing \\
\hline & 1,393 & 1,389 & $(\mathrm{C}-\mathrm{O})$ stretching in ether & Increasing \\
\hline & 1,244 & 1,244 & $(\mathrm{O}-\mathrm{H})$ stanching vibration & Increasing \\
\hline & 1,088 & 1,088 & $(\mathrm{C}=\mathrm{O})$ stanching vibration & Increasing \\
\hline & 815 & 818 & Conjugated double bond & Decreasing \\
\hline & 551 & 551 & $(\mathrm{C}=\mathrm{C})$ stanching vibration in dines & Decreasing \\
\hline
\end{tabular}

In the domain of the $(\mathrm{C}=\mathrm{O})$ stretching vibration (Figs. 9 and 10), one can observe the increase in the intensity of the bands at $1,720 \mathrm{~cm}^{-1}$ and $1,610 \mathrm{~cm}^{-1}$, with blending and increasing in irradiation time, which could be attributed to the formation of $(\mathrm{C}=\mathrm{O})$ groups as a result of photo-oxidation of polymer chains [45].

In the complex region of the $(\mathrm{C}-\mathrm{O})$ stretch and (C-O-H) bend vibration, the increase in the absorption bands of $1,510 \mathrm{~cm}^{-1}, 1,393 \mathrm{~cm}^{-1}, 1,242 \mathrm{~cm}^{-1}$ and 1,046 $\mathrm{cm}^{-1}$ with the increase in irradiation time and blending of polymeric film suggests the formation of mono-substituted benzene ring [27].

The increase in the intensity of the absorption band of $825 \mathrm{~cm}^{-1}$ upon irradiation of polymeric films, may suggest the formation of conjugated double bond sequences in the main polymer chain during the irradiation process. The same observation was noticed by Grassie and Weir [3].

From plots in Figs. 9 and 10, photodegradation and photo-oxidation of PETOS films were enhanced by blending with phthalate and terephthalate plasticizers as well as the increase in irradiation time. 
Table 3 FT IR band position of pure and blended PETOS solid films, before and after (0.0 hr and 3.0 hrs) irradiation at $\left(\lambda_{\text {ext }}=265 \mathrm{~nm}\right)$.

\begin{tabular}{|c|c|c|c|c|}
\hline Polymer & $\begin{array}{l}\text { Band }\left(\mathrm{cm}^{-1}\right) \\
(0.0 \mathrm{~min})\end{array}$ & $\begin{array}{l}\text { Band }\left(\mathrm{cm}^{-1}\right) \\
(120 \mathrm{~min})\end{array}$ & Type of vibration & Intensity \\
\hline \multirow{9}{*}{ PETOS + 10.0\% DMT } & 3,427 & 3,433 & $(\mathrm{O}-\mathrm{H})$ stretching vibration of carboxylic acid & Increasing \\
\hline & 2,922 & 2,924 & $(\mathrm{C}-\mathrm{H})$ stretching vibration of benzene & Increasing \\
\hline & ------ & 1,726 & $(\mathrm{C}=\mathrm{O})$ stanching vibration & New Band \\
\hline & 1,610 & 1,610 & $(\mathrm{C}=\mathrm{C})$ stretching vibration in dines & Increasing \\
\hline & 1,510 & 1,512 & $(\mathrm{C}=\mathrm{O})$ stretching aromatic ketone & Increasing \\
\hline & 1,276 & 1,276 & $(\mathrm{C}-\mathrm{O})$ stretching vibration & Decreasing \\
\hline & 1,049 & 1,049 & (C-O-C) stretching vibration & Increasing \\
\hline & 825 & 829 & Conjugated double bond & Increasing \\
\hline & 550 & 550 & $(\mathrm{C}=\mathrm{C})$ stanching vibration in dines & Increasing \\
\hline \multirow{11}{*}{ PETOS +10.0\%DET } & 3,425 & 3,427 & $(\mathrm{O}-\mathrm{H})$ stretching vibration of carboxylic acid & Increasing \\
\hline & 3,741 & 3,743 & C-O-C stretching vibration & Increasing \\
\hline & 2,922 & 2,924 & $(\mathrm{C}-\mathrm{H})$ stretching vibration of benzene & Increasing \\
\hline & 1,722 & 1,722 & $(\mathrm{C}=\mathrm{O})$ stretching vibration & Increasing \\
\hline & 1,610 & 1,610 & $(\mathrm{C}=\mathrm{C})$ stretching vibration in dines & Increasing \\
\hline & 1,512 & 1,510 & $(\mathrm{C}=\mathrm{O})$ stretching aromatic ketone & Increasing \\
\hline & 1,244 & 1,244 & $(\mathrm{O}-\mathrm{H})$ stanching vibration & Increasing \\
\hline & 1,046 & 1,049 & $(\mathrm{C}=\mathrm{O})$ stanching vibration & Increasing \\
\hline & ------- & 922 & $(=\mathrm{C}-\mathrm{H})$ bending & New band \\
\hline & 825 & 828 & Conjugated double bond & Increasing \\
\hline & 550 & 550 & $(\mathrm{C}=\mathrm{C})$ stanching vibration in dines & Decreasing \\
\hline \multirow{10}{*}{ PETOS +10.0\% DOT } & 3,420 & 3,423 & $(\mathrm{O}-\mathrm{H})$ stretching vibration of carboxylic acid & Increasing \\
\hline & 2,926 & 2,927 & $(\mathrm{C}-\mathrm{H})$ stretching vibration of benzene & Increasing \\
\hline & 1,720 & 1,720 & $(\mathrm{C}=\mathrm{O})$ stretching vibration & Increasing \\
\hline & 1,610 & 1,610 & $(\mathrm{C}=\mathrm{C})$ stretching vibration in dines & Increasing \\
\hline & 1,510 & 1,511 & $(\mathrm{C}=\mathrm{O})$ stretching aromatic ketone & Increasing \\
\hline & 1,393 & 1,393 & $(\mathrm{C}-\mathrm{O})$ stretching in ether & Increasing \\
\hline & 1,242 & 1,244 & $(\mathrm{O}-\mathrm{H})$ stanching vibration & Increasing \\
\hline & 1,046 & 1,048 & $(\mathrm{C}=\mathrm{O})$ stanching vibration & Increasing \\
\hline & 825 & 828 & Conjugated double bond & Decreasing \\
\hline & 550 & 550 & $(\mathrm{C}=\mathrm{C})$ stanching vibration in dines & Decreasing \\
\hline
\end{tabular}

\section{Conclusions}

According to the data obtained on absorption spectra, fluorescence quenching, and FT-IR spectra for the irradiated pure PETOS and blended PETOS with phthalate and terephthalate plasticizers, the following conclusions can be summarized as follows:

Irradiation of pure and blended PETOS films with light of frequency absorbed by polymeric chromophores resulted in an increase in intensity of absorption with the increase in irradiation time of pure polymer film. Another observations are the formation of new absorption band at longer wavelength, and the change in the shape of the absorption spectra, indicating a possibility of photodegradation of polymeric backbone by chain scission as well as photo-oxidation of polymeric chromophores in presence of air.

Irradiation of pure and blended PETOS solid films resulted in the decrease in the intensity of excimer florescence and changes in the shape of the florescence spectrum as well as formation of a small intensity of a broad band at longer wavelength. It was also noticed a small change in the shape of the fluorescence spectra, a small red shift and the increase in the fluorescence intensity of a new broad band 
without clear maxima at longer wavelength (342-378 $\mathrm{nm}$ ), as clearly seen by blending with DOT plasticizer. This may indicate that there is a possibility of photodegradation in the irradiated polymeric chromophores.

The FT IR spectra of irradiate pure PETOS and blended polymer with phthalate and terephthalate plasticizers showed the formation of new absorption band, decrease in the intensity of other bands and the increase in the intensity of most bands in the FT IR spectrum. In the domain of the (C-O) stretching vibration, one observes the appearance of two bands with their maxima at about $1,720 \mathrm{~cm}^{-1}$ and $1,610 \mathrm{~cm}^{-1}$. The increase in their intensity of $1,720 \mathrm{~cm}^{-1}$ band with increase in irradiation time could be attributed to the formation of oxidation products. The increase in the intensity of the band at $1,610 \mathrm{~cm}^{-1}$ may well indicate that aromatic units lose their symmetry throughout the photo-oxidation process. At high region of the FT-IR spectra, the absorption band at $\left(3,423-3,444 \mathrm{~cm}^{-1}\right)$, a noticeable increase in the intensity of the absorption band is observed in the irradiated doped polymer, which can be ascribed to carboxylic acid group (44).

From the data obtained, photo-oxidation of polymeric chains is the main chemical process that occurs during irradiation. Chin scissions are the initial degradation process and are enhanced by plasticization.

It is important for future study to use light energy and thermal energy to obtain data on the analysis of the nature of photoproducts resulted from the degradation process, and write up the proper mechanism of polymer degradation.

\section{References}

[1] Al Ani, K. E., and Ramadhan, A. E. 2015. "Kinetic Study of the Effect of Plasticization on Photodegradation of Polystyrene Solid Films." Mater. Sci. Appl. 6: 617-33. http://dx.doi.org/10.4236/msa.2015.67064.

[2] Weir, N. A. 1978. "Reactions of Hydroxyl Radical with Polystyrene." European Polymer Journal 14: 9-14. http://dx.doi.org/10.1016/0014-3057(78)90144-1.

[3] Grassie, N., and Wier, N. A. 1965. "The Photo-Oxidation of Polymer. II. Photolysis of Polystyrene.” Journal of Applied Polymer Science 9: 975-86. http://dx.doi.org/10.1002/app.1965.070090315.

[4] Lucas, P. C., and Porter, R. S. 1989. "Auto Inhibition in Polystyrene Photo-Oxidation." Polymer Degradation and Stability 26: 203-8. http://dx.doi.org/10.1016/0141-3910(89)90073-6.

[5] David, C., Baeyens-Volant, D., Delaunois, G., Lu-Vinh, Q., Piret, W., and Geuskens, G. 1978. "Photooxidation of Polymers-III Molecular Weight Changes in the Photolysis and Photooxidation of Polystyrene." European Polymer Journal 14: 501-7. http://dx.doi.org/10.1016/0014-3057(78)90037-X.

[6] Al Ani, K. E., and Ramadhan, A. E. 2008. "Photodegradation of Plasticized Poly (Para- Substituted Styrene) in Solution." Polymer Degradation and Stability 93: 1590-6. http://dx.doi.org/10.1016/j.polymdegradstab.2008.04.010.

[7] White, K. R., and Shyichuk, A. V. 2007. "Effect of Stabilization on Scission and Cross-Linking Rate Changes during Photo-Oxidation of Polypropylene." Polymer Degradation and Stability 92: 2095-101. http://dx.doi.org/10.1016/j.polymdegradstab.2007.07.013.

[8] Al Ani, K. E., and Hawi, M. A. 2009. "Effect of Plasticization on the Photodegradation of Poly (Para-Methoxystyrene) Films." Journal of Material Science 44: 2674-8. http://dx.doi.org/10.1007/s10853-009-3350-x.

[9] Al Ani, K. E., and Anabtawi, M. 2012. "UV-Irradiation Effect on the Photodegradation of Plasticized Poly (Ortho, Meta, and Para-Fluorostyrene) Isomers in Solid Films." International Journal of Chemistry 4: 62-84. http://dx.doi.org/10.5539/ijc.v4n5p62.

[10] Al Ani, K. E., and Ramadhan, A. E. 2010. "Study of the Influence of UV-Irradiation on the Photodegradation of Plasticized Poly (Para-Tert-Butylstyrene) Films." International Journal of Material Research 101: 1554-62. http://dx.doi.org/10.3139/146.110434.

[11] Ranby, B., and Rabek, J. F. 1974. "Studies on the Photo-Oxidation Mechanism of Polymers I. Photolysis and Photo-Oxidation of Polystyrene." Journal of Polymer Science, Polymer, Chemistry Edition 12: 273-94. http://dx.doi.org/10.1002/pol.1974.170120203.

[12] Rabek, J. F. 1995. Polymer Photodegradation, Mechanisms and Experimental Methods. London: Chapman and Hall. http://dx.doi.org/10.1007/978-94-011-1274-1.

[13] Kuzina, S. I., and Mikhailov, A. I. 2001. "Photo-Oxidation of Polymers 4. The Dual Mechanism of Polystyrene Photo-Oxidation: A Hydroperoxide and a Photochain One." European Polymer Journal 37: 2319-25. 
http://dx.doi.org/10.1016/S0014-3057(01)00028-3.

[14] Lawrence, J. B., and Weir, N. A. 1973. "Photodecomposition of Polystyrene on Long-Wave Ultraviolet Irradiation: A Possible Mechanism of Initiation of Photooxidation." Journal of Polymer Science: Polymer Chemistry Edition 11: 105-18. http://dx.doi.org/10.1002/pol.1973.170110109.

[15] Luengo, C., Allen, N. S., Edge, M., Wilkinson, A., Parellada, M., Barrio, J. A., and Santa, R. 2006. "Photo-Oxidative Degradation Mechanisms in Styrene-Ethylene-Butadiene-Styrene (SEBS) Triblock Copolymer." Polymer Degradation and Stability 91: 947-56. http://dx.doi.org/10.1016/j.polymdegradstab.2005.06.017.

[16] Kowal, J., and Nwakowska, M. 1982. "Photo-Oxidation of Polystyrene in Dichloromethane Solvent." Polymer 23: 281-2. https://doi.org/10.1016/0032-3861(82)90316-0.

[17] Millan, M. D., Locklin, J., Fulghum, T., Baba, A., and Advincula, R. C. 2003. "Polymer Thin Film Photodegradation and Photochemical Cross-Linking FT-IR Imaging Evanescent Waveguide Spectroscopy, and QCM Investigation." Polymer 46: 5556-68. http://dx.doi.org/10.1016/j.polymer.2005.05.050.

[18] Mailhot, B., and Gardette, J. L. 1992. "Polystyrene Photooxidation. 1. Identification of the IR-Absorbing Photoproducts Formed at Short and Long Wavelengths." Macromolecules 25: 4119-26. http://dx.doi.org/10.1021/ma00042a012.

[19] Geuskens, G., Baeyens-Volant, D., Delaunois, G., Lu-Vinh, Q., Piret, W., and David, C. 1978. "Photo-Oxidation of Polymers-I." European Polymer Journal 14: 291-7. http://dx.doi.org/10.1016/0014-3057(78)90051-4.

[20] David, C., Baeyens-Volant, D., Delaunois, G., Lu-Vinh, Q., Piret, W., and Geuskens, G. 1978. "Photo-Oxidation of Polymers-III." European Polymer Journal 14: 501-7. http://dx.doi.org/10.1016/0014-3057(78)90037-X.

[21] Tovborg Jensen, J. P., and Kops, J. J. 1981. "Energy Transfer in Connection with the Photo-Oxidation of Polystyrene and Its Blends with Poly (2,6-Dimethyl-1, 4-Phenylene Oxide)." Journal of Polymer Science: Polymer Chemistry Edition 19: 2765-71. http://dx.doi.org/10.1002/pol.1981.170191112.

[22] Kobatake, A. T., Okisaki, F., and Shuyama, H. 1995. "Photodegradation of Polystyrene Containing Flame-Retardants: Wavelength Sensitivity and Efficiency of Degradation." Polym Degrad Stab 50: 261-7. http://dx.doi.org/10.1016/0141-3910(95)00143-3.

[23] Choi, W. M., Jung, I. D., Sik, C., and Cho, W. 1998. "Syntheses and Properties of Photodegradable Polystyrene-Containing Carbonyl Group." Journal of Applied Polymer Science 67: 1237-42. http://dx.doi.org/10.1002/(SICI)1097-4628(19980214)67:
7<1237::AID-APP11>3.0.CO;2-Z.

[24] Al Ani, K. E., and Anabtawi, M. 2012. "UV-Irradiation Effect on the Photodegradation of Plasticized Poly(Ortho, Meta, and Para-Fluorostyrene) Isomers in Solid Films." International Journal of Chemistry 4: 62-84. http://dx.doi.org/10.5539/ijc.v4n5p62.

[25] Al Ani, K. E., Ramadhan, A. E., and Al Sieadi, W. N. 2015. "Fourier-Transformation Inferred Spectroscopic Study of Plasticization Effects on the Photodegradation of Poly (Ortho, Meta, and Para-Fluorostyrene) Isomers Films." Journal of Vinyl and Additives Technology 24: 75-83. http://dx.doi.org/10.1002/vnl.21531.

[26] Al Ani, K. E., Ramadhan, A. E., and Anabtawi, M. 2014. "Irradiation Effect on Stability of Plasticized Poly (Fluorostyrene) Isomers in Solution." Int. J. Photochem. 1: 1-12. http://dx.doi.org/10.1155/2014/536068.

[27] Bera, M., Rivaton, A., Gandon, G., and Gardette, J. L. 2000. "Photo-Oxidation of Poly (P-Xylene)." European Polymer Journal 36: 1753-64. http://dx.doi.org/10.1016/S0014-3057(99)00258-X.

[28] Mailhot, B., Jarroux N., and Gardette, J. L. 2000. "Comparative Analysis of the Photo-Oxidation of Polystyrene and Poly ( $\alpha$-Methylstyrene)." Polymer Degradation and Stability 68 (3): 321-26. http://dx.doi.org/10.1016/S0141-3910(00)00016-1.

[29] Weir, N. A. 1982. Developments in Polymer Degradation, edited by N. Grassie. London: Applied Science, 143.

[30] Otocka, E. P., Curran, S., and Porter, R. S. 1983. "Photo-Oxidation of Polystyrene: Irradiation at 254 and 365 nm." Journal of Applied Polymer Science 28 (10): 3227-33. http://dx.doi.org/10.1002/app.1983.070281017.

[31] Geuskens, G., Baeyens-Volant, D., Delaunois, G., Lu-Vinh, Q., Piret, W., and David, C. 1978 "Photo-Oxidation of Polymers-I: A Quantitative Study of the Chemical Reactions Resulting from Irradiation of Polystyrene at $253.7 \mathrm{~nm}$ in the Presence of Oxygen." European Polymer Journal 14: 291-7. http://dx.doi.org/10.1016/0014-3057(78)90051-4.

[32] Kowalonek, J., Kaczmarek, H., and Kurzawa, M. 2016. "Effect of UV-Irradiation on Fluorescence of Poly (Methyl Methacrylate) Films with Photosensitive Organic Compounds." Journal of Photochemistry and Photobiology A: Chemistry 319: 18-24. http://dx.doi.org/10.1016/j.jphotochem.2015.12.017.

[33] Lacoste, J., Carlson, D. J., Falicki, S., and Wiles, M. D. 1991. "Polyethylene Hydroperoxide Decomposition Products." Polymer Degradation and Stability 34: 309-23. http://dx.doi.org/10.1016/0141-3910(91)90125-B.

[34] Al Safi, S. A., Mouamin, M. T., Al Sieadi, W. N., and Al Ani, K. E. 2014. "Irradiation Effect on Photodegradation of Pure and Plasticized Poly (4-Methylstyrene) in Solid Films." Mater. Sci. Appl. 1: 358-68. 


\section{Films with Phthalate and Terephthalate Plasticizers}

http://dx.doi.org/10.4236/msa.2014.55036.

[35] Fields, E. K., and Meyerson, S. 1975. Advances in Free-Radical Chemistry, edited by Williams, G. H. London: Elek Science, 101.

[36] White, K. R., and Shyichuk, A. V. 2007. "Effect of Stabilizer on Scission and Crosslinking Rate Changes during Photo-Oxidation of Polypropylene." Polymer Degradation and Stability 92: 2095-101. http://dx.doi.org/10.1016/j.polymdegradstab.2007.07.013.

[37] Tamai, T., Hashida, I., Ichinose, N., Kawanishi, S., Inoue, H., and Mizuno, K. 1996. "U.V.-Irradiation of Thin Films of Polystyrene Derivatives: Formation of Carboxylic Group and Crosslinking from 4-Trimethylsilylmethyl Substituent." Polymer 37: 5525-8. http://dx.doi.org/10.1016/S0032-3861(96)00438-7.

[38] Weir, N. A., Kutok, P., and Whiting, K. 1989. "Some Aspects of the Long-Wave Photo-Oxidation of Polystyrenes." Polymer Degradation and Stability 24: 247-56. https://doi.org/10.1016/0141-3910(89)90035-9.

[39] Stivala, S. S., Kimum, J., and Reich, L. 1983. "Degradation and Stability of Polymers." In Aspects of Degradation and Stabilization of Polymers, edited by Jellinek, H. G. Amsterdam: Elsevier, 1-66.

[40] Geuskens, G., Bastin, P., Lu-Vinh, Q., and Rens, M. 1981.
"Photo-Oxidation of Polymers: Part IV-Influence of the Processing Conditions on the Photo-Oxidation Stability of Polystyrene." Polymer Degradation and Stability 3: 295-306. https://doi.org/10.1016/0141-3910(81)90025-2.

[41] Al Ani, K. E., Ramadhan, A. E., and Khanfar, S. 2017. "Study the Influence of UV-Irradiation on the Photo Stability of Pure and Plasticized Poly[4-Vinyl Biphenyl] in Solid Films." Mater. Sci. Appl. 8: 1027-52. https://doi.org/10.4236/msa.2017.813075.

[42] Torikai, A., Kobatake, T., Okisaki, F., and Shuyama, H. 1995. "Photodegradation of Polystyrene Containing Fame-Retardant Wavelength Sensitivity and Efficiency of Degradation." Polym. Degrad. Stab. 50 (3): 261-7. http://dx.doi.org/10.1016/0141-3910(95)00143-3.

[43] Torikai, A., Takeuchi, A., and Fueki, K. 1986. "The Effect of Temperature on the Photo-Degradation of Polystyrene." Polym. Degrad. Stab 14 (4): 367-75. http://dx.doi.org/10.1016/0141-3910(86)90040-6.

[44] Lin-Vein, D., Colthup, N. B., Fately, W. G., and Grassley, J. G. 1991. The Handbook of Infra-Red and Raman Characteristic Frequencies of Organic Molecules. Boston: Academic Press.

[45] Pouchert, C. J. (ed.). 1985. The Aldrich Library of Infra Red Spectra (3rd ed.). Milwaukee, WI: Aldrich Co. 